TI 2007-012/3

Tinbergen Institute Discussion Paper

\title{
Modelling the Joint Access Mode and Railway Station Choice
}

Ghebreegziabiher Debrezion ${ }^{1,2}$

Eric Pels'

Piet Rietveld ${ }^{1,2}$

' Free University Amsterdam,

2 Tinbergen Institute. 


\section{Tinbergen Institute}

The Tinbergen Institute is the institute for economic research of the Erasmus Universiteit Rotterdam, Universiteit van Amsterdam, and Vrije Universiteit Amsterdam.

Tinbergen Institute Amsterdam

Roetersstraat 31

1018 WB Amsterdam

The Netherlands

Tel.: $\quad+31(0) 205513500$

Fax: $\quad+31(0) 205513555$

Tinbergen Institute Rotterdam

Burg. Oudlaan 50

3062 PA Rotterdam

The Netherlands

Tel.: $\quad+31(0) 104088900$

Fax: $\quad+31(0) 104089031$

Most TI discussion papers can be downloaded at http:/ /www.tinbergen.nl. 


\title{
Modelling the joint access mode and railway station choice
}

\author{
Ghebreegziabiher Debrezion \\ Eric Pels \\ Piet Rietveld \\ Free University Amsterdam \\ Department of Spatial Economics \\ De Boelelaan 1105 \\ 1081 HV Amsterdam \\ The Netherlands
}

January 2007

\begin{abstract}
:
This study models the choices of Dutch railway users (aggregated at the 4 digit post code area) for access mode and departure railway stations. For each post code area a set of four access modes: car, public transport, bicycle and walking and a set three departure railway stations are identified. A nested logit model is estimated based on 1440 post code areas using a number of access and rail station features. The access features include distance to the departure station, car ownership level, public transport frequency and travel time by public transport to the departure stations. The station features used in the estimation include rail service quality index and supplementary facilities such as availability of parking space and bicycle standing place. Distance has a negative effect on the utility of departure stations. A steeper effect is observed on the choice of departure stations accessed by the non-motorized modes of walking and bicycle. Availability of parking places and bicycle standing areas have a positive effect on the choice of departure railway stations accessed by car and bicycle respectively. Public transport frequency has a positive whereas public transport travel time has a negative effect on the choice of departure stations accessed by public transport. The rail service quality index of a station has a significant and positive effect on the choice of departure stations accessed by all modes.
\end{abstract}

Key words: departure railway station choice, access mode choice, nested logit model. 


\section{INTRODUCTION}

Railway transport constitutes a sizable share of daily travel made by Dutch travellers. The figures from the Central Bureau of Statistics (CBS) in 2002 reveal that railway transportation in the Netherlands accounts for about $8 \%$ of the overall passenger kilometres. This figure is one of the highest shares of railway transport in Europe and the world. In the US, the overall public transport share (which includes railway and bus services) is about $2 \%$ (U.S. DOT 2005). The modal split of passenger kilometres shares for the 15 Members States of the European Union are also given in Table 1. After Austria and France, railway transport in the Netherlands accounts for highest share of the total passenger kilometres. On the other hand, it is necessary to be aware that the railways' share in the number of trips is considerably lower, since railway trips tend to be much longer than those of other modes.

Once the decision to travel by train is made, some of the logical questions that follow are: 1) Which station to use for departure?; 2) Which access mode to use to get to the station?; and 3) Which route to follow to the destination? The decisions on these types of choice are affected by different factors. Bovy and Stern distinguish three factors: 1) features of the available alternatives; 2) characteristics of the traveller; and 3) features of the choice situation (Bovy and Stern 1990). This paper is a study on the first two types of choice faced by railway travellers mentioned above. These are the choice of departure railway station, and the choice of access mode to the railway station. The paper does not attempt to address the issue of route choice to a destination. The trip from the origin to the departure station is called the access part, while the trip from the destination station to the final destination is called the egress part. This paper addresses the two basic choices made by railway travellers concerning the access part of a train trip: access mode and departure station choices.

The choice of a departure station is influenced by two types of factors: factors related to the accessibility of the station, and factors related to the rail services provided at the station. Easily accessible railway stations are more likely to be selected as departure stations than less accessible stations. For instance, keeping other things constant, stations served by frequent public transport modes are expected to be preferred to stations which have less-frequent public transport services as departure stations. Similarly, the availability of other access modes such as car, public transport, and other non-motorized modes is expected to influence the choice of a departure railway station. Moreover, the choice of a departure station also 
depends on the quality of the station itself. The quality of a railway station is generally explained by the quality of rail and supplementary services provided at the station. The frequency of train services, network connectivity, and coverage are some examples of the rail service. The presence of other supplementary facilities such as the availability of parking spaces, the park-and-ride possibility, bike stands and storage facilities (lock-ups) also boost the attractiveness of a station as a departure station.

Table 1: Modal split by country for passenger transport (in passenger kilometres share): EU15 (5 modes) in 2002

\begin{tabular}{lrrrrr}
\hline & CAR & BUS & RAILWAY & TRAM \& METRO & AIR \\
\hline BELGIUM & 79.8 & 9.9 & 6.0 & 0.7 & 3.6 \\
DENMARK & 74.3 & 11.1 & 6.8 & & 7.8 \\
GERMANY & 78.8 & 8.6 & 7.8 & 0.9 & 3.9 \\
GREECE & 65.9 & 17.0 & 1.4 & 1.0 & 14.6 \\
SPAIN & 71.2 & 10.6 & 4.5 & 1.2 & 12.5 \\
FRANCE & 83.1 & 4.5 & 8.2 & 1.2 & 3.0 \\
IRELAND & 72.8 & 12.4 & 3.2 & & 11.5 \\
ITALY & 80.2 & 11.0 & 5.3 & 0.6 & 3.0 \\
LUXEMBOURG & 74.7 & 12.8 & 5.1 & & 7.4 \\
NETHERLANDS & 81.5 & 4.1 & 8.1 & 0.8 & 5.5 \\
AUSTRIA & 70.7 & 13.6 & 8.4 & 2.8 & 4.5 \\
PORTUGAL & 79.7 & 8.3 & 3.1 & 0.5 & 8.3 \\
FINLAND & 77.7 & 10.3 & 4.4 & 0.7 & 7.0 \\
SWEDEN & 74.0 & 8.0 & 7.2 & 1.8 & 9.0 \\
UNITED KINGDOM & 80.9 & 5.9 & 5.1 & 1.1 & 7.1 \\
\hline
\end{tabular}

Source: Adapted from EU energy and transport in figures: statistical pocket book 2004

Revealed choice data for departure stations for Dutch railway travellers shows that, in about $47 \%$ of the cases, passengers choose a departure station which is not the nearest station to their places of residence. This indicates that using distance to the railway station for measuring railway accessibility has some limitations and also that differences in station quality have to be considered. In the literature four types of stations are identified: commuter railway stations; heavy railway stations; light railway stations; and bus rapid transit (BRT) stations (see Debrezion et al. 2006). However, also with such distinctions we still observe heterogeneity among stations of the same type. Thus, there is a need for a more refined approach to analysing the attractiveness of railway stations. The first component of such an approach concerns the ease of reaching the station. Distance from the origin to the departure station can be taken as a general proxy. In addition, because accessing the railway station can be done by different modes of transport, mode-related features are also important factors in the determination of the ease of accessing the railway station. Features related to the quality of road access and public transport can be mentioned. Supplementary station services such as 
the availability of parking space and bike stands also contribute to the access mode choice. The second component relates to the level of rail service that is delivered at the railway station. This is the subject of Section 3 of this paper.

By applying these railway station accessibility concepts, this paper aims to analyse the choice process of Dutch travellers for access mode and departure stations. This will, in turn, be used to calculate a general railway accessibility index for zones where people live. In most real estate price studies, railway station accessibility is just given by the distance to the nearest railway station from the property in question. However, railway station accessibility encompasses more aspects that are involved in the choice process for a departure station. Understanding the valuation and decision mechanism leading to the choices of departure station and access mode has several practical implications for the formulation of transportation management policy for urban areas. In the first place, it enables us to define the catchment areas (market areas) of stations. This means that it enhances the prediction of travel demand at station level. This in turn can be used as a basis for site selection for the development of new lines or planning extensions for existing lines, as well as parking facilities and feeder public transport operation planning. In addition, the understanding of the sensitivity of travellers towards the access and station features gives a station operator the basis for increasing travellers' turnover.

The paper is organized as follows: Section 2 briefly reviews the literature in the area. Section 3 discusses the computation of the Rail Service Quality Index of a railway station. Section 4 gives the specification of the nested logit model which is applied in the estimations of this paper. In Section 5, we discuss the specification of the utility models for the access-mode departure station choice. In Section 6, we describe the data used in our analysis. Section 7 gives the estimation results, followed by the discussion of these results. Section 8 ends the paper with summaries and conclusions.

\section{LITERATURE REVIEW}

The literature on access mode and departure station choice is limited. One of the early rail transit station choice models was developed by Kastrenakes (1988) in an effort to prepare a basis for forecasting railway travel in the New Jersey area. With origin-destination pair data, 
he analysed the choice process for a departure station by considering of the access time required to reach the station, the frequency of service at the boarding station, whether the boarding station is located in the locality of the passenger's residence, and the generalized cost of the train trip between the departure station and the destination station (Kastrenakes 1988). The study found, as expected, positive effects for frequency of service and location of the station in the locality of the passenger's residential area on the probability of departure station choice. Similarly, the expected negative effects were found for access time and the generalized cost of the rail trip. In another study, Wardman and Whelan (1999) studied railway station choice for the London area. This study was done in relation to parking attractiveness for station choice. It was indicated that the availability of a parking area in a station and other station facilities are important features for station choice (Wardman and Whelan 1999).

Some studies on this theme have also incorporated access mode choice in a nested structure (Fan et al. 1993; Wardman and Whelan 1999; and Davidson and Yang 1999). Generally, the access mode choice at the upper-level of the nest was the accepted structure rather than the reverse order. Fan et al. (1993) included several variables for the transit station choice. Travel time (including access and in-vehicle time), fare, peak-hour frequency of trains, and the number of parking places were among the included variables. As expected it was found that the coefficients for frequency of service and parking had a positive sign and coefficients for travel time and fare had a negative sign. Wardman and Whelan (1999) on the other hand, compared the access mode-station choice for business and leisure travellers. They found the value of time is highest for business trips and lower for leisure trips. Other variables included were journey time, journey headway, facilities at the station, and parking availability. They all show expected the signs and significant effects on the choice of the departure station.

Choice analysis of this form has been popular in the literature on airport and airline choice (Ashford and Bencheman 1987; Hess and Polak 2004; Pels et al. 2001; Pels et al. 2003; and Basar and Bhat 2004). Fares (airport tax), access time, frequency of service, and other facilities are important features used in airport choice. Some studies also include time-series historic data in the choice features of those commuters who tend to keep on using an airport that they have previously used. The analyses of departure airports have some relevance to the railway station choice. Most of the time, the fare difference between railway stations are not observed. Thus, the fare does not play a relevant role in the choice among stations. However, 
access features like access time and access cost are obviously relevant for the railway station analysis. The frequency of service, as indicated by the number of trains leaving the station per given time interval and/or the number of destinations served directly from the station, plays an important role in station choice analysis. The same holds for the nature of the station and facilities at the station. Obviously, international and intercity stations are expected to enjoy higher choice probabilities compared with express or stop train stations ${ }^{1}$. Stations with better public and passenger-related facilities are also expected to be more attractive compared with stations with less or no facilities. The attractiveness of the station as a departure station declines as the access time increases.

\section{RAIL SERVICE QUALITY INDEX}

Railway stations differ from each other in rail services they offer to passengers. In several empirical applications it has been noted that there is a need for a station classification based on the service levels. Our data set includes some indicators of rail service at the station level. The indicators are the daily frequency of trains leaving the station, the number of destinations having a direct connection with the station under consideration, and the intercity status of the station. By including these factors in the choice analysis we account for the rail service quality of a station. However, the usefulness of these factors is limited because they do not take into account the location of the station in relation to important destinations. Thus, in addition to the factors mentioned above, the importance of destination stations and distances are determinants of the service quality of a station. The need for a comprehensive rail service quality indicator for each railway station leads us to an estimation exercise based on underlying railway trip data. A doubly constrained gravity model for trips between an origin railway station $i$ and a destination railway station $j$ was selected to estimate the coefficients (Fotheringham and O'Kelly 1989; and Ortúzar and Willumsen 2001). The importance of the destination station can be measured by the size of trip attraction capacity of the destination station. In addition, the total travel time reflects the relative location, connectedness and frequency of service. The doubly constrained spatial interaction model is given by:

\footnotetext{
${ }^{1}$ In the Netherlands there are four types of railway services: namely, the all-station rail services called 'stop train'; 'semi-fast' also called 'express' rail services which call at main and medium cities; 'intercity'rail services that only call at main cities; and international trains that only stop at a very limited number of stations.
} 


$$
\begin{aligned}
T_{i j} & =A_{i} O_{i} B_{j} D_{j} f\left(G J T_{i j}\right) g\left(G J T_{i j} / d_{i j}\right) \exp \left(\xi_{i j}\right) \\
O_{i} & =\sum_{j} T_{i j} \\
D_{j} & =\sum_{i} T_{i j}
\end{aligned}
$$

where $T_{i j}$ is the number of trips between stations $i$ and $j ; O_{i}$ is the total number of trips originated in station $i ; D_{j}$ is the total number of trips attracted by station $j . A_{i}$ and $B_{j}$ are the balancing factors which ensure that the constraints on origins and destinations (given by equation 2 and 3) are met; The reason that we cannot make use of a standard distance decay function in this context is that our estimation is confined to trips by train. This leads to two possible diversions from the ordinary pattern: first the function may be increasing in stead of decreasing for short distance trips since non-motorised transport modes and local public transport will in general outperform the train in this domain. Second, we may have to take into account the possibility that trains make detours compared with other transport modes having implications for the train's modal share. $f\left(G J T_{i j}\right)$ is a function of the generalized journey time between stations $i$ and $j^{2}$; generalized journey time is a measure of the time needed to travel between the stations. It includes the average waiting time, in vehicle time, transfer time and some penalty for the number of transfers. The generalized journey time measure encompasses several station distinctive features of stations. For instance, the frequency of trains leaving the station per unit of time is reflected in the average waiting time component. The distinction of railway station as intercity, semi fast and stop train is expected to be reflected in the transfer time and number of transfer penalties. Intercity train stations provide more direct services. This leads to less in-vehicle and transfer time, and thus, less generalized travel time than semi fast and stop train stations. In addition, the transfer time and penalty for transfers shows the level of direct connections a station has with other stations.

The function $f\left(G J T_{i j}\right)$ is specified as follows:

$$
f\left(G J T_{i j}\right)=\sum_{c=1}^{C} \beta_{c} D G J T_{c}^{i j}
$$

\footnotetext{
${ }^{2}$ Generalized Journey Time (GJT) as calculated by NS is given as $\mathrm{GJT}_{\mathrm{ij}}=1 /\left(2 *\right.$ frequency $\left._{\mathrm{ij}}\right)+$ invehicle time $_{\mathrm{ij}}+$ transfer time $\mathrm{ij}_{\mathrm{ij}}+10 *$ number of transfers $\mathrm{ij}_{\mathrm{ij}}$
} 
This function is a stepwise function of the generalized journey time. $D G J T_{c}^{i j}$ is a dummy variable which is equal to 1 if $G J T_{i j}$ falls in the generalized journey time category $c$ and zero otherwise. In our estimation we used 46 categories of generalized journey time of 10 minute intervals.

The function $g\left(G J T_{i j} / d_{i j}\right)$ depends on the generalized journey time and the road distance ratio between stations $i$ and $j$. Distance in this function is given by the Euclidian distance between the two stations. This factor is expected to accommodate the effect of detour train trips on the use of train. A high value of $G J T_{i j} / d_{i j}$ would imply that the train is relatively unattractive compared with other transport modes, implying a lower propensity to travel by train on that route. The function $g\left(G J T_{i j} / d_{i j}\right)$ is specified as follows:

$g\left(G J T_{i j} / d_{i j}\right)=\left(G J T_{i j} / d_{i j}\right)^{\gamma}$

Lastly, $\xi_{i j}$ is the error component of the model which follows an independently and identically normal distribution.

Thus, the doubly constrained gravity model we estimated is given by:

$T_{i j}=A_{i} O_{i} B_{j} D_{j}\left(\sum_{c=1}^{c} \beta_{c} D G J T_{c}^{i j}\right)\left(G J T_{i j} / d_{i j}\right)^{\gamma} \exp \left(\xi_{i j}\right)$

This equation can be linearized by taking the natural logarithm of both sides:

$$
\ln \left(T_{i j} / O_{i} D_{j}\right)=\ln A_{i}+\ln B_{j}+\ln \left(\sum_{c=1}^{C} \beta_{c} D G J T_{c}^{i j}\right)+\gamma \ln \left(G J T_{i j} / d_{i j}\right)+\xi_{i j}
$$

The coefficient of the generalized journey time categories, the ratio of generalized journey time, and the balancing factors will be estimated from the above equation. Thus, in the estimation the logs of the balancing factors in the equation represent the coefficients to be estimated. This requires that the logs of the balancing factors are multiplied by the dummy variable for the corresponding station. Therefore, the equation for the estimation is given as: 


$$
\ln \left(\frac{T_{i j}}{O_{i} D_{j}}\right)=\sum_{\tilde{i}=1}^{N} \ln A_{\tilde{i}} S_{\tilde{i}}+\sum_{\tilde{j}=1}^{N} \ln B_{\tilde{j}} S_{\tilde{j}}+\ln \left(\sum_{c=1}^{C} \beta_{c} D G J T_{c}^{i j}\right)+\gamma \ln \left(\frac{G J T_{i j}}{d_{i j}}\right)+\xi_{i j}
$$

Where, $N$ is the number of railway stations in the railway network; and $S_{\tilde{i}}$ and $S_{\tilde{j}}$ are dummy variables for departure station $\tilde{i}$ and destination station $\widetilde{j}$. They assume the value 1 when $i=\tilde{i}$ and $j=\tilde{j}$, respectively, and 0 otherwise. Given the assumption on the error components above, Equation 8 can be estimated using ordinary least squares (OLS). The estimated coefficients are then used in determining the rail service quality indices (RSQIs) for each station. From any departure station, the index is determined by the generalized journey time, the size of the destination station, given by the trips attracted by the destination station, and the generalized journey time and distance ratio. The RSQI of station $i$ is determined as the aggregation sum of the quality measures over all the destination stations ( $j$ 's) from station $i$. Thus, the RSQI of a given departure station is given by:

$$
R S Q I_{i}=\sum_{j} \hat{B}_{j} D_{j} \hat{f}\left(G J T_{i j}\right) \hat{f}\left(\frac{G J T_{i j}}{d_{i j}}\right)=\sum_{j} \hat{B}_{j} D_{j}\left(\sum_{c=1}^{C} \hat{\beta}_{c} D G J T_{c}^{i j}\right)\left(\frac{G J T_{i j}}{d_{i j}}\right)^{\hat{\gamma}} ;
$$

The estimation of the doubly constrained model given by equation 8 is based on the train trips from 365 departure railway stations to 365 destination train stations. The data were acquired from the Dutch Railway company (NS). The data set includes the number of trips, generalized journey time and distance between each pairs of stations. Trips originating and ending at a station are determined by aggregation of the trips over all destination and departure stations respectively. During the analysis it was necessary to make some computational considerations. On some pairs of stations there were no trips. Taking the logarithm of these values leads to the exclusion of these entries from the estimation. To avoid this problem, some value had to be added to find a positive value for the number of trips between the pairs of station. Sen and Smith (1995) have proven that the optimal value that can be added is $1 / 2$. Following that result, our final estimation of the parameters is based on the actual trips plus half a trip.

The estimation results of Equation 8 are given in Table 2. The reported estimations relate to the coefficients of the stepwise generalized journey time and generalized journey time to distance ratio. The estimates for the balancing factors are not reported for reason of limited 
space. For trip durations of up to 30 minutes, train trips are increasing with time. This indicates that for shorter trips the train encounters competition from other modes. Apparently, the competition effect presented by the generalized journey time to distance ratio does not completely capture the competition phenomena. A possible explanation is that, for shorter trips, people tend to use other modes such as bicycle and public transport rather than the train. Trips between points within cities are generally expected to be accommodated by walking, biking, car or public transport because of the flexibility they offer. For trip duration of over 30 minutes, the usual distance (in this case time) decay pattern is found.

Table 2: Estimation result of the doubly-constrained interaction model

\begin{tabular}{|l|r|r|}
\hline Variable & Coefficient & \multicolumn{1}{l|}{} \\
\hline GJT0_10 & 8.642 & 21.027 \\
\hline GJT10_20 & 9.261 & 24.837 \\
\hline GJT20_30 & 9.351 & 25.160 \\
\hline GJT30_40 & 8.736 & 23.525 \\
\hline GJT40_50 & 8.114 & 21.859 \\
\hline GJT50_60 & 7.561 & 20.378 \\
\hline GJT60_70 & 7.025 & 18.943 \\
\hline GJT70_80 & 6.414 & 17.302 \\
\hline GJT80_90 & 5.917 & 15.965 \\
\hline GJT90_100 & 5.482 & 14.796 \\
\hline GJT100_110 & 5.066 & 13.676 \\
\hline GJT110_120 & 4.684 & 12.644 \\
\hline GJT120_130 & 4.424 & 11.944 \\
\hline GJT130_140 & 4.137 & 11.170 \\
\hline GJT140_150 & 3.913 & 10.567 \\
\hline GJT150_160 & 3.742 & 10.106 \\
\hline GJT160_170 & 3.550 & 9.588 \\
\hline GJT170_180 & 3.391 & 9.157 \\
\hline GJT180_190 & 3.214 & 8.682 \\
\hline GJT190_200 & 3.083 & 8.328 \\
\hline GJT200_210 & 2.850 & 7.697 \\
\hline GJT210_220 & 2.739 & 7.397 \\
\hline GJT220_230 & 2.552 & 6.893 \\
\hline
\end{tabular}

\begin{tabular}{|l|r|r|}
\hline Variable & Coefficient & \multicolumn{1}{l|}{ T } \\
\hline GJT230_240 & 2.386 & 6.444 \\
\hline GJT240_250 & 2.208 & 5.964 \\
\hline GJT250_260 & 2.061 & 5.566 \\
\hline GJT260_270 & 1.930 & 5.212 \\
\hline GJT270_280 & 1.829 & 4.939 \\
\hline GJT280_290 & 1.623 & 4.382 \\
\hline GJT290_300 & 1.539 & 4.155 \\
\hline GJT300_310 & 1.369 & 3.693 \\
\hline GJT310_320 & 1.280 & 3.451 \\
\hline GJT320_330 & 1.094 & 2.946 \\
\hline GJT330_340 & 0.995 & 2.675 \\
\hline GJT340_350 & 0.913 & 2.452 \\
\hline GJT350_360 & 0.842 & 2.261 \\
\hline GJT360_370 & 0.758 & 2.035 \\
\hline GJT370_380 & 0.718 & 1.927 \\
\hline GJT380_390 & 0.823 & 2.203 \\
\hline GJT390_400 & 0.831 & 2.214 \\
\hline GJT400_410 & 0.681 & 1.805 \\
\hline GJT410_420 & 0.664 & 1.712 \\
\hline GJT420_430 & 0.730 & 1.841 \\
\hline GJT430_440 & 0.493 & 1.168 \\
\hline Ln(GJT/dist) & -0.399 & -37.449 \\
\hline R-square & 0.998 \\
\hline
\end{tabular}

In addition, the negative coefficient for generalized journey time to distance ratio imply train trips decline with increase on the ratio. If the train trip involves detours, this implies the generalized travel time increases, and thus the ratio. The fact that the train trip involves longer detours makes other modes of transport preferable. 


\section{THE NESTED LOGIT MODEL}

We apply a nested logit model to model the choices made concerning the departure railway station and access mode to the departure railway station by Dutch railway travellers. The model has two levels, so there are two possible decision structures. In one of these two structures, alternatives that have the same access mode are grouped together. In the other setup, alternatives with the same departure station are grouped together (Hensher and Greene 2002). We will analyse both structures to determine which structure is appropriate to model the choice behaviour. Next we will specify the econometric model.

We assume that the decision structure has two levels. There are $K$ alternatives which can be grouped into $J$ nests, in which each nest has $N_{j}$ alternatives. The final choice can be regarded as a choice concerning the combination of choices on both levels. Suppose the utility of the final choice for the choice maker is:

$U_{j k}=V_{j k}+\varepsilon_{j k}$,

where, $V_{j k}$ is the systematic utility of the final choice; and $\varepsilon_{j k}$ is the non-systematic part of the utility for the final choice. If we assume that $\varepsilon_{j k}$ are iid Gumbel extreme-value distributed, the probability of the outcome can be given by the logit model:

$P_{j k}=\frac{\exp \left(V_{j k}\right)}{\sum_{m \in J} \sum_{l \in K_{m}} \exp \left(V_{m l}\right)}$.

In the nested logit model we distinguish between utility of alternatives and utility of nests. The utilility of alternative $k$ in nest $j$ is defined as:

$V_{k \mid j}=\boldsymbol{\beta}^{\prime} \mathbf{x}_{k \mid j}$.

Where, $\mathrm{x}$ is a vector of features related to the elemental choices (access mode-departure station combinations); and $\boldsymbol{\beta}$ is a vector of the corresponding coefficients. The choice of a nest is based on the utility of the nest, which includes the expected utility (or inclusive value) of the alternatives within the nest. The expected systematic utility $(\tilde{V})$ at the nest level is given by: 
$\tilde{V}_{j}=V_{j}+\frac{1}{\mu_{j}} \ln \sum_{l \in K_{j}} \exp \left(\mu_{j} V_{l \mid j}\right)$.

Where $\mu_{j}$ is a scaling parameter. The scaling parameter at the upper level of the decision tree is normalised to 1 . This normalization option of the scaling parameters is generally referred as RU2. The logit models based on RU2 are consistent with Random Utility Maximization theory when the scaling parameters $\left(\mu_{j}\right)$ are greater than 1 . Thus, the probabilities for both the elemental and the structural choices can be given as:

$$
\begin{aligned}
& P_{k \mid j}=\frac{\exp \left(\mu_{j} V_{k \mid j}\right)}{\sum_{l \in K_{j}} \mu_{j} V_{l \mid j}}=\frac{\exp \left(\mu_{j} \boldsymbol{\beta}^{\prime} \mathrm{x}_{k \mid j}\right)}{\sum_{l \in K_{j}} \exp \left(\mu_{j} \boldsymbol{\beta}^{\prime} \mathrm{x}_{l \mid j}\right)}, \\
& P_{j}=\frac{\exp \left(\tilde{V}_{j}\right)}{\sum_{m \in J} \exp \left(\tilde{V}_{m}\right)}=\frac{\exp \left(\boldsymbol{\gamma}^{\prime} \mathrm{y}_{j}+1 / \mu_{j}\left(\ln \left(\sum_{k \in K_{j}} \exp \left(\mu_{j} \boldsymbol{\beta}^{\prime} \mathrm{x}_{k \mid j}\right)\right)\right)\right.}{\sum_{m \in J} \exp \left(\boldsymbol{\gamma}^{\prime} \mathrm{y}_{m}+1 / \mu_{m}\left(\ln \left(\sum_{m \in M_{j}} \exp \left(\mu_{j} \boldsymbol{\beta}^{\prime} \mathrm{x}_{m \mid j}\right)\right)\right)\right.} .
\end{aligned}
$$

The joint probability is given by $P_{j k}=P_{k \mid j} \times P_{j}$.

The parameters in $P_{j k}$ are estimated using maximum likelihood. $1 / \mu_{j}$ is known as the 'inclusive value parameter' since it is the estimated coefficient of the expected utility of the alternatives included in the nest.. It can be interpreted as a measure of dissimilarity between alternatives within a nest. It is an indicator of the correlation in the unobserved components of the utilities of the choices grouped under nest $j$. The smaller the value of the inclusive value parameter $\left(1 / \mu_{j}, \mu_{j}>1\right)$, the higher is the correlation between the alternatives in the nest. It can also be shown that $\left(1-1 / \mu_{j}^{2}\right)$ is equal to the correlation of the utilities of alternatives within nest $j$ (Ben-Akiva and Lerman 1985). If $\mu_{j}=1$, the situation is characterized by complete independence among the alternatives in the nest. This suggests that there is no need for grouping the alternatives in nests, and thus the nested logit model collapses into the multinomial logit model. 


\section{UTILITY SPECIFICATION}

We start with the assumption that the passenger in our analysis has already decided to travel by train. The passenger then faces two related choices: 1) the choice of the access mode $(a \in A)$ to take in order to reach a station; and 2) the choice of the departure station $(d \in D)$. Both choices are made simultaneously: travellers choose a combination of access mode and a departure railway station. We distinguish two choice structures (as discussed in the previous section). The inclusive value parameters given by the estimation give an indication of which nest structure is appropriate for modelling the choice analysis (it is necessary that $\mu>1$ ). Next, we will discuss the specifications of the utility model for both structures.

\subsection{Access mode- departure station}

This nest structure puts the access mode in the upper-level and the choice of a departure station at the lower-level. This structure is motivated by the fact that the unobserved components of station utilities accessed by the same mode of transportation are correlated. The decision tree for this choice can be depicted in Figure 1 below.

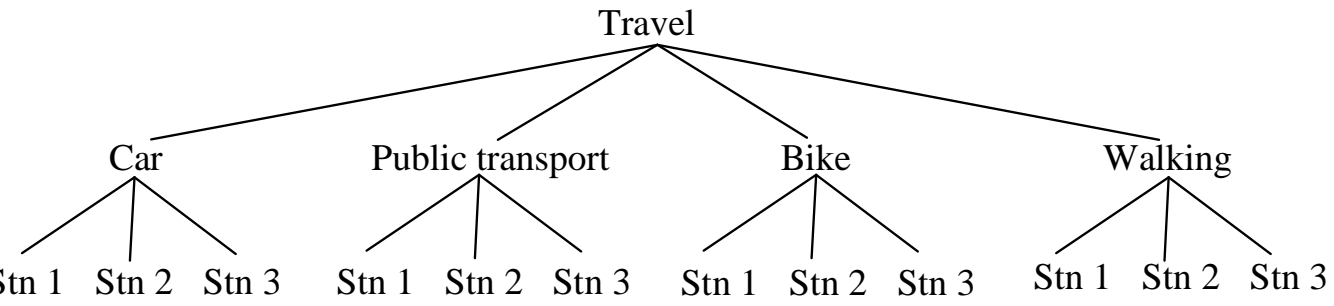

Figure 1: Access mode departure station choice decision tree

Let us start by specifying the utility of the branch (access mode) level. We assume a linear functional form for the underlying utilities. As indicated in the next section, a distinguishing feature of our data set is that data are not available at the individual level, but at the level of postcode areas. As a consequence, we cannot make use of information on individual choice sets, for example, whether or not a car is in the choice set. To deal with this problem, the utility functions are formulated as follows:

$$
\begin{aligned}
& V(\text { car })=\alpha_{\text {car }}+\beta_{\text {car_carown }} * \text { carownership } \\
& V(P T)=\alpha_{P T}+\beta_{P T_{-} \text {carown }} * \text { carownership } ; \\
& V(\text { bike })=\alpha_{B k}+\beta_{B k_{-} \text {carown }} * \text { carownership } ;
\end{aligned}
$$


$V($ walk $)=0$.

Where, $V($.$) gives the systematic utility of the access modes; carownership is the level of car$ ownership in the postcode area; the $\beta$ 's are the coefficients for the effect of car ownership on the utility level of corresponding access modes. The mode-specific constants account for the mode related characteristics. The effect of the car ownership effect on the choice of access modes is expected to explain the substitution/competition effect between car as an access mode and the other alternative modes. A positive coefficient for car ownership implies that an increase in car ownership promotes the use of the specified mode. On the other hand, a negative coefficient implies that an increase in car ownership discourages the use of the specified mode. We expect an increase in the car ownership level in the postcode area to promote the use of the car access mode and to discourage the use of the other access modes. However, the negative effect is expected to be more intense on the longer-distance-oriented motorized mode: namely, public transport, than on bike and walking. The walking mode is set to serve as a reference point for the other modes.

The lower-level choice relates to the departure station choice. The station choice utilities are assumed to be determined by characteristics related to the stations and characteristics linking the access mode and the stations. Thus, we adopt a generic utility formulation for the departure-station choice quality. Differentiations are only made on the basis of which mode is used to access the stations. The station characteristics are given by the rail service quality index (RSQI) determined in Section 3. Even though the distance variable enters the systematic utilities of the stations, it may have a different implication for the departure-station utility based on the access modes applied. Thus, we differentiate the effect of distance to the station by access mode. Distance is expected to have a negative effect on the utility in all four cases. However, the magnitude of the effect is expected to be higher for short-distanceoriented modes than long-distance-oriented modes. The utilities attached to each of the access modes are expected to decline with distance. In general, the RSQI of the station is expected to have a positive impact on the utilities of the departure station accessed by all modes. The presence of supplementary station facilities are also expected to be access-mode-related. For instance, the presence of a parking area at the station is only expected to affect the utility of departure stations accessed by the car mode. It is expected to have a positive effect on the utility of stations accessed by car mode. Similarly, a bicycle stand is expected to influence the choice of station accessed by bike. A positive effect is expected. Public transport travel time 
and frequency influence the choice of departure railway station accessed by public transport. The frequency of public transport is expected to have a positive effect on the utility of departure stations accessed by public transport. On the other hand, public transport travel time is expected to negatively affect the utility of the stations accessed by public transport. Given the access mode, the systematic utility functions of a departure station are given:

$$
\begin{aligned}
& V\left(\text { station }_{k} \mid \text { car }\right)=\beta_{\text {cardist }} \times \text { dist }_{k}+\beta_{R S Q I} \times R S Q I_{k}+\beta_{\text {parkcar }} \times \text { parking }_{k} ; \\
& V\left(\text { station }_{k} \mid p t\right)=\beta_{\text {PTdist }} \times \text { dist }_{k}+\beta_{R S Q I} \times R S Q I_{k}+\beta_{\text {PTtravltime }} \times \text { PTtraveltime }_{k} \\
& +\beta_{\text {PTfreq }} \times \text { PTfreq }_{k} \text {; } \\
& V\left(\text { station }_{k} \mid p t\right)=\beta_{\text {bikedist }} \times \text { dist }_{k}+\beta_{R S Q I} \times R S Q I_{k}+\beta_{\text {bikestand }} \times \text { bikestand }_{k} ; \\
& V\left(\text { station }_{k} \mid \text { walk }\right)=\beta_{\text {walkdist }} \times \text { dist }_{k}+\beta_{R S Q I} \times R S Q I_{k} .
\end{aligned}
$$

Where, $k \in K=\{1,2,3\}$ is an element of the set of departure stations for the postcode area; dist is the distance from the centroid of the postcode area to the railway station considered; $R S Q I$ is the rail service quality index; parking is a dummy variable indicating the presence of a parking area in or around the railway station; PTtraveltime is the average public transport travel time from the postcode area to the railway station given in minutes; PTfreq is the average public transport frequency of service from the postcode area to the railway station given by the number of services per hour; and bikestand is a dummy variable indicator for the presence of bicycle stand at the railway station.

\subsection{Departure station-access mode}

An alternative way of arranging the choices concerning departure station and access mode is to put the departure station on the upper-level and the access mode choice at the lower-level of the nest, as depicted by Figure 2. This grouping assumes that there are similarities between access modes that are used to access the same departure station.

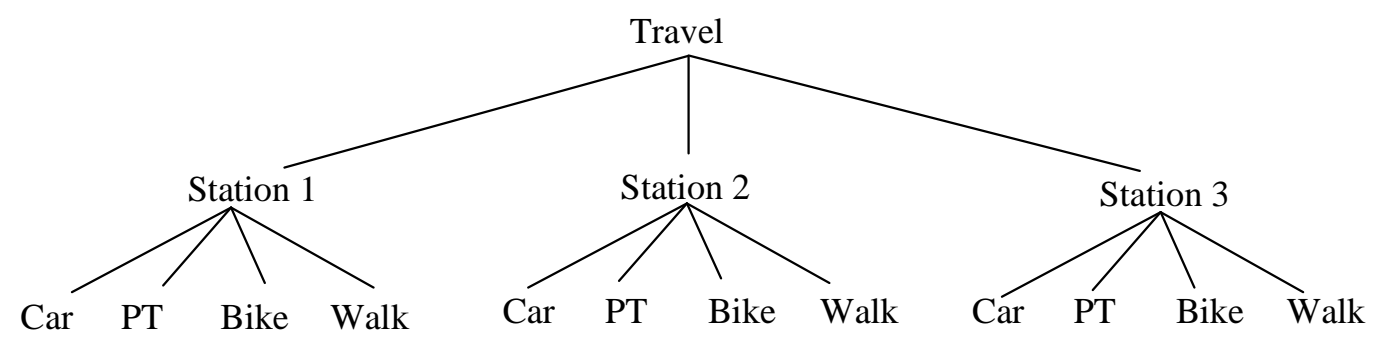

Figure 2: Departure station-access mode choice decision tree. 
We assume the utilities of the upper-level choice alternatives: namely, concerning the choice of a departure station, are affected by the RSQI determined earlier in Section 3. The generic departure station utility function is given Equation 25 below:

$V\left(\right.$ station $\left._{k}\right)=\beta_{R S Q I} \times R S Q I_{k}$

A number of variables explain the utility functions for the access modes. To account for the mode-specific effects, the functions include the corresponding mode-specific coefficients. No prior expectations are made on the sign or magnitude of the coefficients. Car ownership levels are expected to affect the utility of all modes. The inclusion of car ownership in the utility specification is aimed at capturing the competition effect. The walking mode is taken as the reference group. The utility specifications for the access modes also include the distance and station features that are related to the specific access mode. The distance effect is assumed to be mode-specific. Some railway station features are also expected to affect the utilities of certain access modes, and not others. For instance, the availability of a parking area in or around the station is related to car access mode. Similarly, the presence of a bicycle stand at a station is a feature related to the bicycle access mode. The specifications for the different access-mode choice utilities, given that station $k$ is chosen as a departure station, are given by Equations 25-28. The variables are explained in the previous subsection.

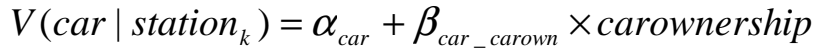

$$
\begin{aligned}
& +\beta_{\text {cardist }} \times \text { dist }_{k}+\beta_{\text {parkar }} \times \text { parking }_{k} ; \\
& V\left(p t \mid \text { station }_{k}\right)=\alpha_{P T}+\beta_{P T_{-} \text {carown }} \times \text { carownership }+\beta_{P T d i s t} \times \text { dist }_{k} \\
& +\beta_{\text {PTravlime }} \times \text { PTtraveltime }_{k}+\beta_{\text {PTfreq }} \times \text { PTfreq }_{k} ; \\
& V\left(\text { bike } \mid \text { station }_{k}\right)=\alpha_{B K}+\beta_{B K_{-} \text {carown }} \times \text { carownership } \\
& +\beta_{\text {bikedist }} \times \text { dist }_{k}+\beta_{\text {bikestand }} \times \text { bikestand }_{k} \text {; } \\
& V\left(\text { walk }_{\text {station }_{k}}\right)=\beta_{\text {walkdist }} \times \text { dist }_{k} .
\end{aligned}
$$




\section{DATA}

The data used in our analysis were obtained from the Dutch National Railway Company (Nederlandse Spoorwegen-NS). A postcode area is the unit of analysis. Household choices for access mode and departure railway station are aggregated at this level of zoning. The final analysis is based on 1440 postcode areas. For each of the postcode areas, a set of three departure stations is identified. In most cases the set accounts for the three most frequentlyused departure railway stations in the postcode area. The set of departure stations for each postcode area are ranked according to the size of the share of usage they account for as departure stations. This means the first station accounts for the highest share of usage as a departure station in the postcode area, whereas the third station accounts for the smallest of the three. In total 346 railway stations are included in the analysis. In addition, a set of four alternative access modes is defined for each postcode area: car, public transport, bike and walking. All four access modes are assumed to be available for each postcode area. All choices are given in shares because of the aggregated nature of the data. Thus, the final choice explains the joint share of access-mode and departure station choices made in the postcode areas. Each postcode area faces 12 access mode and departure-station choice combinations.

The data set incorporates several features related to the railway stations and access modes. The car ownership level is one of the relevant features given at the postcode area level. At the station level, we find data for the RSQI, availability of parking areas, and availability of bike stands. Public transport data on frequency and travel time were retrieved from the public transport timetables of the lines linking the postcode area and each of the alternative departure stations. The public transport timetables are available at the 6-digit postcode level an area comprising up to about 20 houses, and were aggregated to the 4-digit postcode level an area composed of about seven 6-digit areas. GIS information on the location of the centroid of the postcode area and the railway stations was used to determine the distance measure to represent the accessibility indicator. Thus, our data set includes the usage share of the three most frequently-chosen stations for each postcode area and the railway station features of each station including the distance between the centroid of the postcode area and the railway station. 


\section{Description of Station and Access-mode Characteristics}

As has been previously discussed in this paper, we assume railway attractiveness in a zone is explained by two factors: the ease of reaching railway stations, and the service levels provided at the stations. The ease of reaching the stations is linked to the quality of public transport linking to the station and the distance between the departure point (the centroid of the postcode area in this case) and the railway station. On the other hand, the level of services provided at the stations is related to the frequency of trains leaving the station per period of time and network connectivity, as determined by the number of destinations that can be reached without transfer. The RSQI (see Section 3) is determined from the generalized journey time between stations; the importance of the destination station; and the ratio of the generalized journey time to the distance. The attractiveness of a station can also be affected by facilities that supplement railway transport. Parking areas, the availability of a park-andride facility, and bike stands can be mentioned. The choice probabilities of access-mode and departure-station in the postcode areas are summarized in Table 3 below $^{3}$. It is based on the access mode - departure station tree structure of choices. Public transport, with about $38 \%$ of the share, is the most frequently used access mode by which passengers reach the railway station. On the departure station side, on average the first most frequently-chosen railway station accounts for about $77 \%$ of the total share. The second and third most frequentlychosen railway stations account for $17 \%$ and $6 \%$, respectively.

Table 3: Summaries of choice probabilities of departure station and access mode

\begin{tabular}{|l|l|r|r|}
\hline & Departure station & Branch level & Choice level \\
\hline Car & $1^{\text {st }}$ Station & 0.2376 & 0.1596 \\
\hline & $2^{\text {nd }}$ Station & & 0.0527 \\
\hline & $3^{\text {rd }}$ Station & & 0.0253 \\
\hline Public transport & $1^{\text {st }}$ Station & 0.3765 & 0.2862 \\
\hline & $2^{\text {nd }}$ Station & & 0.0680 \\
\hline & $3^{\text {rd }}$ Station & 0.2443 & 0.0223 \\
\hline Bicycle & $1^{\text {st }}$ Station & & 0.2056 \\
\hline & $2^{\text {nd }}$ Station & & 0.0309 \\
\hline & $3^{\text {rd }}$ Station & 0.1416 & 0.0078 \\
\hline Walking & $1^{\text {st }}$ Station & & 0.1220 \\
\hline & $2^{\text {nd }}$ Station & & 0.0162 \\
\hline & $3^{\text {rd }}$ Station & & 0.0034 \\
\hline
\end{tabular}

\footnotetext{
${ }^{3}$ These are unweighted averages across post code areas. When postcode areas would be weighted according to the number of railway travelers, the bicycle share in access mode choice would be higher.
} 
Table 4 below gives the descriptive statistics of railway station characteristics and the accessibility indicators for the postcode areas. For the purpose of showing the variation in Table 4, we only give the statistic on the distance of the most frequently-chosen station from the postcode area. It also gives the railway station features. Included are the indicators of RSQI and supplementary facilities; frequency and travel times of public transport service; car ownership level in the postcode areas; and distance measure to railway stations.

Table 4: Descriptive statistics for the railway station characteristics (2001/2002)

\begin{tabular}{|l|c|c|c|c|c|}
\hline Description & $\begin{array}{c}\text { No. of } \\
\text { stations/ } \\
\text { postcode areas }\end{array}$ & Min & Max & Mean & $\begin{array}{c}\text { Std. } \\
\text { Deviation }\end{array}$ \\
\hline Rail service quality index (RSQI) & 365 & 0.03 & 2.00 & 0.43 & 0.33 \\
\hline Bicycle stand & 96 & 0 & 1 & 0.28 & \\
\hline Parking & 318 & 0 & 1 & 0.91 & \\
\hline Accessibility from postcode areas & & & & & \\
\hline Distance to the most frequently-chosen station (m) & 1400 & 95 & 31,708 & 5,840 & 5,583 \\
\hline Car ownership in the postcode area & 1440 & 0.11 & 0.99 & 0.40 & 0.09 \\
\hline Frequency of public transport (vehicle per hour) & 1440 & 1.00 & 19.00 & 1.98 & 2.14 \\
\hline Public transport travel time (minutes) & 1440 & 2.00 & 57.91 & 25.41 & 12.81 \\
\hline
\end{tabular}

\section{ESTIMATION AND DISCUSSION}

The estimation results of the nested logit model for the two nest structures discussed above are given in Tables 5 and 6 below. The inclusive value parameters in the estimations give us an indication as to which nesting structure is more appropriate for modelling the choice behaviour. The two estimations are readily comparable since they use the same normalization procedure for the scaling parameters in the model. The scaling parameter is normalized at the upper-level, and the lower-level scaling parameters are free. This model is generally referred to as the 'Random Utility Model 2' (RU2). For the model outcome to be consistent with random utility maximization, the inclusive value parameters should be greater than 1 . A value which is equal to 1 indicates a complete collapse of the nested logit model as a multinomial logit model. Generally speaking, most variables in the estimations have significant and expected effects. However, the inclusive value parameters in the departure-station - accessmode nest structure fall below 1. This indicates that this structure is not appropriate for nesting the choices. On the other hand, the inclusive value parameter estimates based on the access-mode - departure-station choice structure are above 1. Thus, this nesting structure seems more appropriate for the choices than the reverse order nest. Our discussion will, therefore, focus on the estimation result of the access-mode - departure-station nest structure. 
Table 5: Estimation results for access-

mode - departure-railway station decision

nest (RU2)

\begin{tabular}{|c|c|c|c|}
\hline Variable & Coefficient & Z-value & P-value \\
\hline \multicolumn{4}{|c|}{ Lower-level parameters } \\
\hline RSQI & 1.0654 & 8.652 & 0.000 \\
\hline CAR_DIST & -0.1088 & -8.539 & 0.000 \\
\hline PARK_CAR & 0.9348 & 2.777 & 0.006 \\
\hline PT_DIST & -0.0472 & -4.506 & 0.000 \\
\hline PT_FREQ & 0.1057 & 5.148 & 0.000 \\
\hline PT_TIME & -0.0108 & -2.275 & 0.023 \\
\hline BK_DIST & -0.4833 & -13.643 & 0.000 \\
\hline BIKE_STAND & 0.3800 & 3.737 & 0.000 \\
\hline WK_DIST & -1.1222 & -13.030 & 0.000 \\
\hline \multicolumn{4}{|c|}{ Upper-level parameters } \\
\hline ALPHA_CAR & -3.7989 & -6.608 & 0.000 \\
\hline CAR_CAROWN & 0.7536 & 0.702 & 0.483 \\
\hline ALPHA_PT & -0.8643 & -2.035 & 0.042 \\
\hline PT_CAROWN & -4.2328 & -4.512 & 0.000 \\
\hline ALPHA_BIKE & -1.0871 & -2.735 & 0.006 \\
\hline BK_CAROWN & 0.3372 & 0.359 & 0.720 \\
\hline \multicolumn{4}{|c|}{ Inclusive value parameters $(\mu)$} \\
\hline CAR & 1.628 & 10.995 & 0.000 \\
\hline PUBLICT & 1.628 & 10.995 & 0.000 \\
\hline BIKE & 1.628 & 10.995 & 0.000 \\
\hline WALKING & 1.628 & 10.995 & 0.000 \\
\hline \multicolumn{4}{|c|}{ number of observations $=17280$} \\
\hline log likelihood function & \multicolumn{3}{|c|}{$=-2678.118$} \\
\hline \multicolumn{2}{|c|}{ Restricted log likelihood } & \multicolumn{2}{|c|}{$=-3578.266$} \\
\hline Chi squared & \multicolumn{3}{|c|}{$=1800.295$} \\
\hline Degrees of freedom & \multicolumn{3}{|c|}{$=16$} \\
\hline Prob[ChiSqd > value] & \multicolumn{3}{|c|}{$=0.0000$} \\
\hline R-sqrd & \multicolumn{3}{|c|}{$=0.25156$} \\
\hline RsqAdj & \multicolumn{3}{|c|}{$=0.25080$} \\
\hline
\end{tabular}

Table 6: Estimation results for departure railway station-access -mode decision nest (RU2)

\begin{tabular}{|c|c|c|c|}
\hline Variable & Coefficient & Z-value & P-value \\
\hline Lower-level paran & & & \\
\hline ALPHA_CAR & -7.754 & -5.820 & 0.000 \\
\hline CAR_CAROWN & 1.545 & 0.776 & 0.438 \\
\hline CAR_DIST & -0.150 & -8.161 & 0.000 \\
\hline PARK_CAR & 2.040 & 2.259 & 0.024 \\
\hline ALPHA_PT & -1.653 & -2.162 & 0.031 \\
\hline PT_CAROWN & -8.523 & -4.595 & 0.000 \\
\hline PT_DIST & -0.029 & -1.596 & 0.111 \\
\hline PT_TIME & -0.022 & -2.202 & 0.028 \\
\hline PTFREQ & 0.225 & 5.608 & 0.000 \\
\hline ALPHA_BIKE & -2.347 & -3.002 & 0.003 \\
\hline BK_CAROWN & 0.574 & 0.320 & 0.749 \\
\hline BIKE_DIST & -0.878 & -13.616 & 0.000 \\
\hline BIKE_STAND & 1.115 & 4.798 & 0.000 \\
\hline WALK_DIST & -2.219 & -11.196 & 0.000 \\
\hline Upper-level param & & & \\
\hline RSQI & 1.576 & 11.614 & 0.000 \\
\hline Inclusive value pa & neters $(\mu)$ & & \\
\hline STATION 1 & 0.495 & 10.364 & 0.000 \\
\hline STATION 2 & 0.495 & 10.364 & 0.000 \\
\hline STATION 3 & 0.495 & 10.364 & 0.000 \\
\hline number of observa & $=172$ & & \\
\hline log likelihood fun & $=-268$ & 0.225 & \\
\hline Restricted log like & $=-357$ & 8.266 & \\
\hline Chi squared & $=179$ & .082 & \\
\hline Degrees of freedor & $=16$ & & \\
\hline Prob [ChiSqd > va & $=0.00$ & 000 & \\
\hline R-sqrd & $=0.25$ & 072 & \\
\hline RsqAdj & $=0.2$ & 996 & \\
\hline
\end{tabular}




\subsection{Effect of station's rail service quality}

The estimation results show that the measure of the rail service quality index (RSQI) has a positive and significant effect on the choice of departure stations. In addition, the presence of supplementary facilities at the stations also has a positive impact on the choice of a departure station. The presence of a parking area and bike stands have a positive and significant effect on the choice of departure stations accessed by car and bike, respectively. The elasticities of the RSQI on the choice probability of access mode and departure station are presented in Table 7 below.

Table 7: Direct elasticity of rail service quality index (RSQI)

\begin{tabular}{|l|l|r|r|r|}
\hline \multirow{2}{*}{ Access mode } & \multirow{2}{*}{ Departure station } & \multicolumn{3}{|c|}{ Elasticity } \\
\cline { 3 - 5 } Car & Branch level & Choice level & Total elasticity \\
\hline & $1^{\text {st }}$ Station & 0.313 & 0.519 & 0.832 \\
\hline & $2^{\text {nd }}$ Station & 0.231 & 0.689 & 0.92 \\
\hline Public transport & $3^{\text {rd }}$ Station & 0.171 & 0.723 & 0.894 \\
\hline & $1^{\text {st }}$ Station & 0.286 & 0.537 & 0.823 \\
\hline & $2^{\text {nd }}$ Station & 0.187 & 0.763 & 0.95 \\
\hline Bicycle & $3^{\text {rd }}$ Station & 0.134 & 0.806 & 0.94 \\
\hline & $1^{\text {st }}$ Station & 0.37 & 0.28 & 0.649 \\
\hline & $2^{\text {nd }}$ Station & 0.24 & 0.612 & 0.851 \\
\hline Walking & $3^{\text {rd }}$ Station & 0.171 & 0.659 & 0.83 \\
\hline & $1^{\text {st }}$ Station & 0.378 & 0.136 & 0.514 \\
\hline & $2^{\text {nd }}$ Station & 0.264 & 0.392 & 0.656 \\
\hline & $3^{\text {rd }}$ Station & 0.221 & 0.484 & 0.705 \\
\hline
\end{tabular}

The choice level represents the departure stations accessed by a given access mode. The three stations accessed by a given mode are arranged according to the size of their market share in the postcode area. The $1^{\text {st }}$ station is the most frequently-chosen station in the postcode area. The table shows that the elasticity of the RSQI on the choice level increases as we go from the biggest station to the smallest station accessed by all modes. For example, a $1 \%$ increase in the RSQI of railway stations accessed by the car mode leads to an increase in the choice probability of the station by $0.52 \%, 0.69 \%$, and $0.72 \%$ for the $1^{\text {st }}, 2^{\text {nd }}$, and $3^{\text {rd }}$ stations, respectively. The trend of the effect is consistent with the intuitive expectation, in that an increase in a station's RSQI is expected to a have higher impact on the stations with the lowest share. Note that the elasticities given in the table represent direct elasticities. Crosselasticities are not reported. An increase in the service quality of a railway station leads to an increase in demand. The travel demand increase experienced in one station comes at the expense of the demand at the other railway stations accessed by the same mode of transport 
and railway stations accessed by other modes. Because of the higher similarity between railway stations accessed by the same access mode, changes in the RSQI of a station are expected to result in a stronger substitution between the stations within the nest than outside the nest. Thus, the cross-elasticity of rail service quality of a station is expected to be higher for a station within one nest than for stations across nests. To illustrate the effect of change in the rail service quality of a station on the choice share, consider the case of the station with the highest share. The direct and cross-elasticities of rail service quality change of the $1^{\text {st }}$ station accessed by car mode are given below, in Table 8 .

Table 8: Direct and cross-elasticities of rail service quality index for the station with the highest share

\begin{tabular}{|l|l|r|r|r|}
\hline \multirow{2}{*}{ Access mode } & \multirow{3}{*}{ Departure station } & \multicolumn{3}{|c|}{ Elasticity } \\
\cline { 3 - 5 } & $1^{\text {st }}$ Station & Branch level & Choice level & Total elasticity \\
\hline & $2^{\text {nd }}$ Station & 0.313 & 0.519 & 0.832 \\
\hline & $3^{\text {rd }}$ Station & 0.201 & -0.462 & -0.261 \\
\hline Public transport & $1^{\text {st }}$ Station & 0.193 & -0.451 & -0.258 \\
\hline & $2^{\text {nd }}$ Station & 0.286 & 0.537 & 0.823 \\
\hline & $3^{\text {rd }}$ Station & 0.170 & -0.515 & -0.345 \\
\hline Bicycle & $1^{\text {st }}$ Station & 0.161 & -0.504 & -0.343 \\
\hline & $2^{\text {nd }}$ Station & 0.370 & 0.280 & 0.649 \\
\hline & $3^{\text {rd }}$ Station & 0.228 & -0.548 & -0.320 \\
\hline Walking & $1^{\text {st }}$ Station & 0.207 & -0.493 & -0.286 \\
\hline & $2^{\text {nd }}$ Station & 0.378 & 0.136 & 0.514 \\
\hline & $3^{\text {rd }}$ Station & 0.177 & -0.403 & -0.226 \\
\hline & & 0.167 & -0.370 & -0.203 \\
\hline
\end{tabular}

Based on these elasticities, we can compute the share of each station for any change in the $1^{\text {st }}$ station's share. For comparison purposes, we give the change of shares as a result of a $10 \%$, $50 \%$, and $100 \%$ increase in the rail service quality of the $1^{\text {st }}$ station. The resulting shares are given in Table 9 below. As the RSQI increases, the share of the $1^{\text {st }}$ station increases. This leads to a decrease in the shares of other stations. This is true for all stations accessed by the different modes. For example, a doubling in the RSQI of the $1^{\text {st }}$ stations leads to an increase of its market share from $77 \%$ to $90 \%$. Our model also indicates that the effect of an increase in the RSQI has bigger effects on the $2^{\text {nd }}$ station compared with the effect on the $1^{\text {st }}$ and $3^{\text {rd }}$ stations. This is because of an already high share and thus saturation, whereas in the case of the $3^{\text {rd }}$ station the baseline share is still too low. This leaves the $2^{\text {nd }}$ station to be the station with a bigger potential for share increase. A doubling of the RSQI of the second station results in an increase of its market share from $17 \%$ to $32 \%$. 
Table 9: The effect of change in the RSQI of the station with the biggest share accessed

\begin{tabular}{|l|l|l|l|l|r|}
\hline Access mode & $\begin{array}{l}\text { Departure } \\
\text { station }\end{array}$ & $\begin{array}{l}\text { Base } \\
\text { shares }\end{array}$ & \multicolumn{2}{l|}{$\begin{array}{l}\text { Share after 10\% } \\
\text { increase in the } \\
\text { RSQI }\end{array}$} & \multicolumn{2}{l|}{$\begin{array}{l}\text { Share after 50\% } \\
\text { increase in the } \\
\text { RSQI }\end{array}$} & \multicolumn{2}{l|}{$\begin{array}{l}\text { lnare after 100\% } \\
\text { increase in the } \\
\text { RSQI }\end{array}$} \\
\hline Car & $1^{\text {st }}$ Station & 0.1596 & 0.1647 & 0.1810 & 0.1954 \\
\hline & $2^{\text {nd }}$ Station & 0.0527 & 0.0489 & 0.0367 & 0.0260 \\
\hline & $3^{\text {rd }}$ Station & 0.0253 & 0.0235 & 0.0177 & 0.0125 \\
\hline Public transport & $1^{\text {st }}$ Station & 0.2862 & 0.2951 & 0.3236 & 0.3486 \\
\hline & $2^{\text {nd }}$ Station & 0.0680 & 0.0625 & 0.0451 & 0.0298 \\
\hline & $3^{\text {rd }}$ Station & 0.0223 & 0.0205 & 0.0148 & 0.0098 \\
\hline Bicycle & $1^{\text {st }}$ Station & 0.2056 & 0.2086 & 0.2181 & 0.2265 \\
\hline & $2^{\text {nd }}$ Station & 0.0309 & 0.0285 & 0.0208 & 0.0140 \\
\hline & $3^{\text {rd }}$ Station & 0.0078 & 0.0072 & 0.0054 & 0.0037 \\
\hline Walking & $1^{\text {st }}$ Station & 0.1220 & 0.1222 & 0.1228 & 0.1234 \\
\hline & $2^{\text {nd }}$ Station & 0.0162 & 0.0151 & 0.0115 & 0.0084 \\
\hline & $3^{\text {rd }}$ Station & 0.0034 & 0.0032 & 0.0024 & 0.0018 \\
\hline
\end{tabular}

\subsection{Effect of distance on access mode choice}

We next move to the choice of access mode as a function of distance to a railway station. We compare the access modes for a zone with average levels of car ownership ( 0.402 cars per person) and average speed and frequency of local public transport. Based on these figures, the utility level of the access modes are plotted in Figure 3. Distance is given on the X-axis. All utility curves are downward-sloping, showing the decline in the utility as the distance increases. At any point along the distance range, the utility of one access mode is dominant. We can safely say the access mode corresponding to the dominating utility curve is the most probable mode of access to the departure station in the interval in which its utility is dominant. The graph indicates that walking is the most probable access mode choice for the distance range of up to 1.1 kilometres. In the range of distances between $1.1 \mathrm{~km}$ and $4.2 \mathrm{~km}$ the bicycle is the most probable access mode choice. Beyond this point, public transport dominates the car alternative, thus, for longer distances public transport remains the most probable access mode choice.

The estimation can be used to predict the shift of the break-even point between bike and public transport when frequency of public transport would double. In that case this point shifts from $4.2 \mathrm{~km}$ to $3.6 \mathrm{~km}$. 


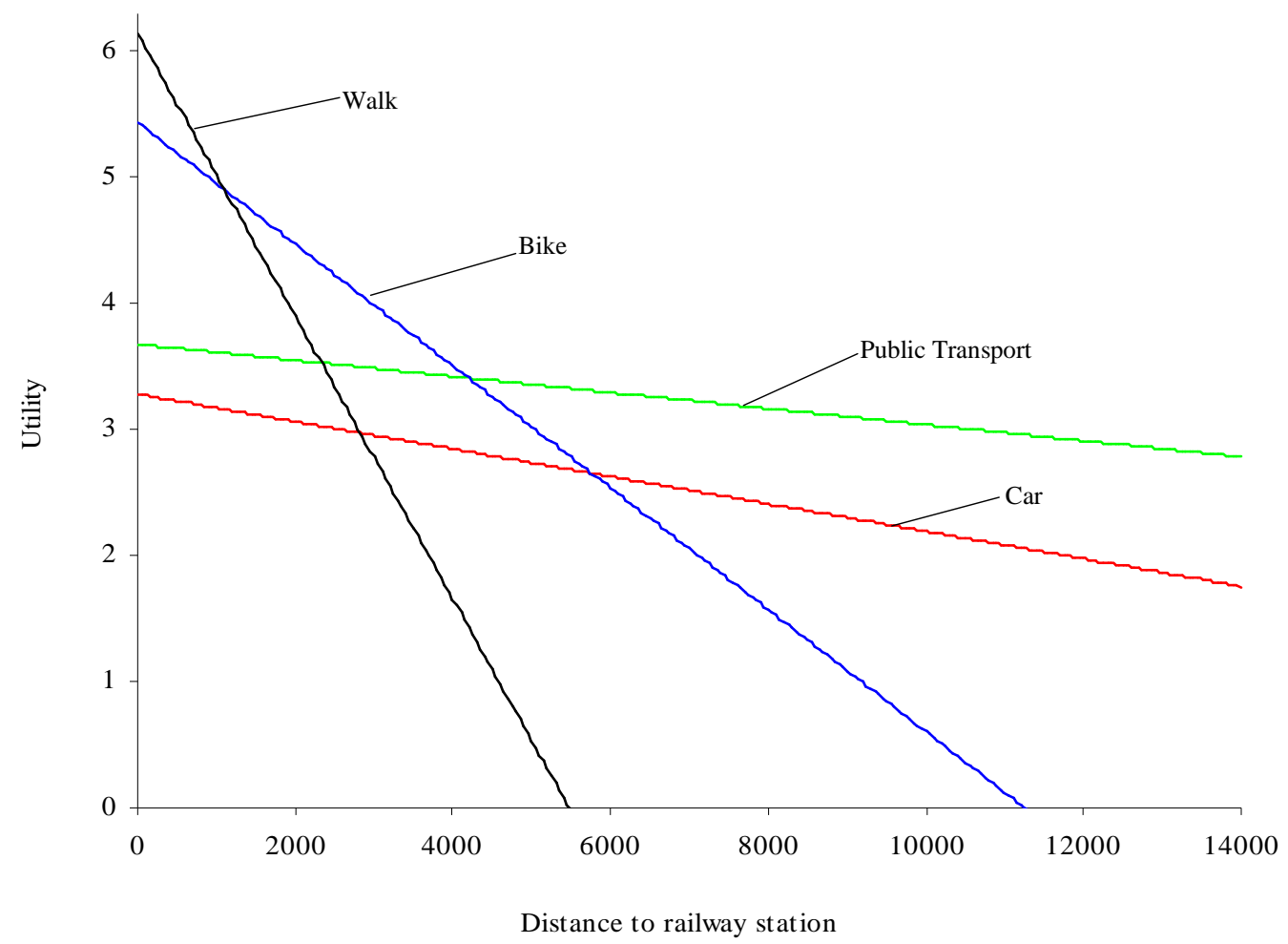

Figure 3: The utilities of access modes with respect to distance, for a car ownership level of 0.402 cars per person

\subsection{The effect of car ownership}

Along similar lines we explore the effect of car ownership in a postcode area on the choice of access mode. Note that in Figure 3 which represents an area with an average car ownership level the utility curve for the car is always below that of public transport, which implies that the choice probability for the public transport access mode is higher than that of the car for all access distances. Figure 4 shows what happens when car ownership would move up to 60 per person. In that case public transport is no longer dominating on all distances: from around 10 kilometres the car starts to dominate public transport. 


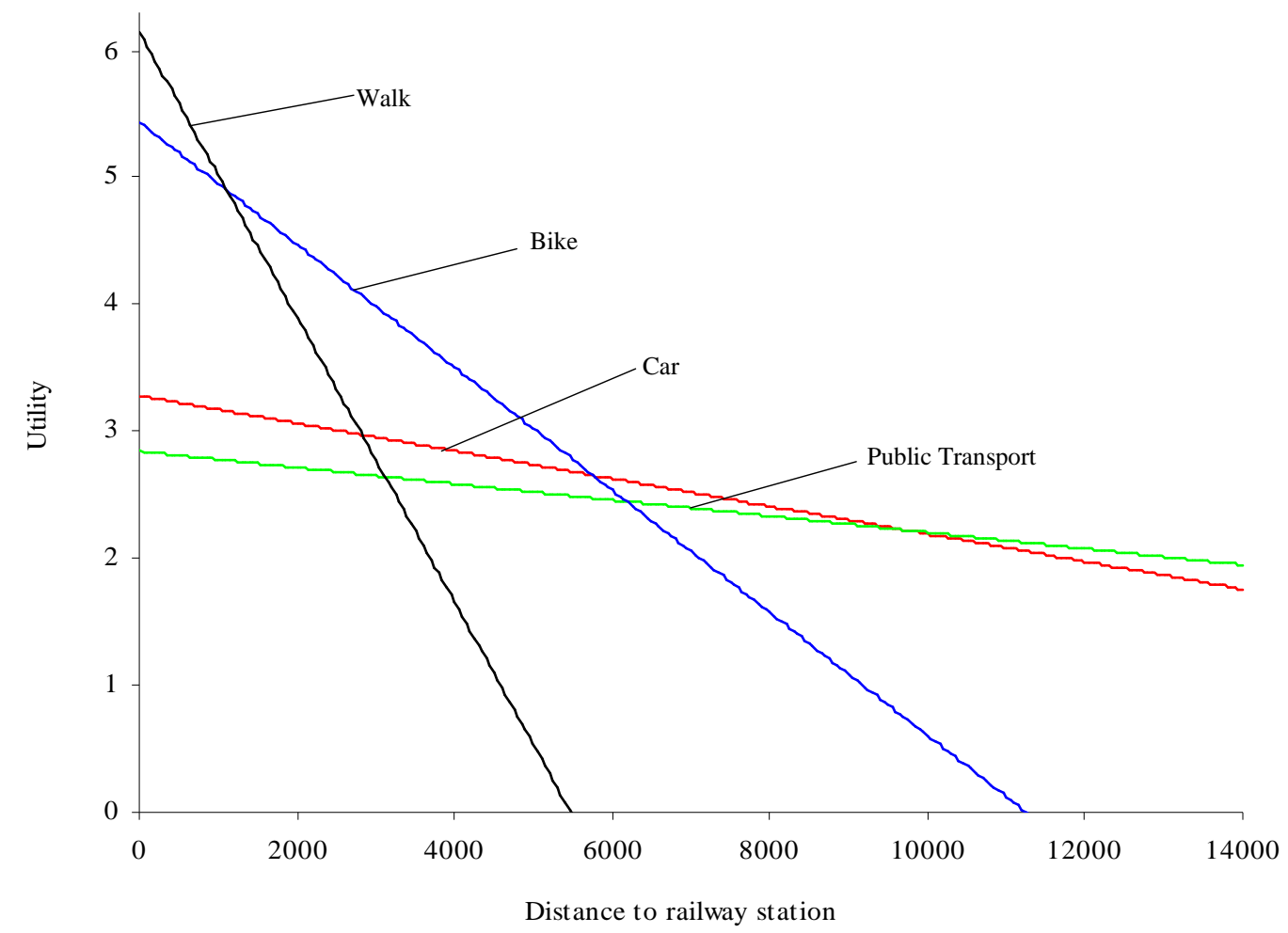

Figure 4: The utilities of access modes with respect to distance, for a car ownership level of .60 cars per person

\section{CONCLUSION}

A distinguishing feature of this study is that we developed a railway quality index to study the effect of the level of service on railway station choice by travellers. This index incorporates elements like frequency, speed and attractiveness of destinations of the rail services.

A nested logit model was applied to explain choice behaviour concerning departure station and access mode. The model was estimated based on 1440 postcode areas using a number of access and rail station features. Two structures were analysed. We find that the access mode departure station choice nesting (from up to down) structure seems more appropriate for the choices than the reverse order nest. The station features used in the estimation include a railway station quality index (RSQI) and supplementary facilities such as availability of parking space and bicycle stands. The study found the access-mode - departure-station 
choice nest structure is more appropriate to model the choice process compared with the reverse nest structure. All variables have a significant effect on the choice of access mode and departure station. Distance has a negative effect on the choice of departure station. A steeper effect is observed on the choice of departure stations accessed by the non-motorized modes of walking and bicycle. This implies that they are used on shorter access distances. The level of car ownership has a positive but insignificant effect on the choice of car access mode and a negative effect on the use of public transport. The availability of parking places and bicycle stands has a positive effect on the choice of departure-railway stations accessed by car and bicycle, respectively. Public transport frequency has a positive effect, whereas public transport travel time has a negative effect on the choice of departure stations accessed by public transport. The derived RSQI of a station has a significant and positive effect on the choice of departure stations accessed by all modes. The elasticity of the RSQI on the choice of departure station increases as we go from the $1^{\text {st }}$ station with the highest share to the $3^{\text {rd }}$ station with the lowest share for all access mode cases. However, the elasticities are generally higher for the motorized case compared with the non-motorized ones.

We also find that doubling the frequency of local public transport has a modest effect on access mode choice: it leads to a decrease of the break-even distance for bike and public transport from 4.2 to 3.6 kilometres.

\section{Acknowledgement:}

We would like to take the opportunity to thank different parties that contributed to our work by providing data and financial support. The Dutch national Railway Company (NS) was helpful at every stage by providing data and insightful ideas. Special thanks go to Mark van Hagen and his colleagues at NS. The financial support for this and related researches was provided by NWO, Habiforum and Transumo. 


\section{Reference:}

Ashford, N., Benchemam, M., (1987). Passengers' choice of airport: an application of the multinomial logit model. Transportation Research Record, 1147, 1-5.

Ben-Akiva M. (1973). Structure of Travel Passenger Demand Models, Ph. D. Dissertation, MIT.

Ben-Akiva, M. and S. Lerman, (1985). Discrete Choice Analysis: Theory and Application to Travel Demand. MIT Press, Cambridge, MA.

Bovy, P. H. L. \& E. Stern (1990). Route Choice: Way finding in Transport Networks. Kluwer Academic Publishers, Boston, MA.

Davidson, Bill and Lidan Yang (1999). Modeling commuter rail station choice and access mode combinations. Presented at the Transportation research Board annual meeting, Washington D.C., 10-14 January 1999.

Debrezion, Ghebreegziabiher, Eric Pels and Piet Rietveld (2006). The Impact of Railway Stations on Residential and Commercial Property value: A Meta-Analysis. Journal of Real Estate Finance and Economics, Forthcoming.

Fan, K., E. Miller, and D. Badoe (1993). Modeling Rail Access Mode and Station Choice. Transportation Research Record 1413, 1993, 49-59.

Fortheringham, A.S. and M.E. O'Kelly, (1989). Spatial Interaction Models: Formulations and Applications. Kluwer Academic Publishers, Dordrecht, the Netherlands.

Hess, Stephane and John W. Polak (2005). Mixed Logit Modeling of Airport choice in Multi-Airport Regions. Journal of Air Transport Management, 11 (2), 59-68.

Kastrenakes, C.R. (1988). Development of a Rail Station Choice Model for NJ Transit," Transportation Research Record 1162, 16-21.

Lythgoe, W. F., M. Wardman and J. P. Toner (2004) Enhancing Rail Passenger Demand models to Examine Station Choice and Access to the Rail Network. AET European Transport Conference, PTRC, London.

Ortúzar, J.D., L.G. Willumsen (2001). Modelling Transport. John Wiley \& Sons, Ltd, Chichester, UK.

Pels, Eric, Peter Nijkamp and Piet Rietveld (2003). Access to and competition between airports: a case study for the San Francisco Bay area. Transportation Research Part A 37, 71-83.

Sen, Ashish and Tony Smith (1995). Gravity Models of Spatial Interaction behaviour, SpringerVerlag, Berlin.

Wardman, M., and G. A. Whelan (1999). Using Geographical information systems to improve rail demand models. Final report to Engineering and Physical science Research council.

Vrtic, M. und K.W. Axhausen (2003). The impact of tilting trains in Switzerland: A route choice model of regional- and long distance public transport trips. Presented at the $82^{\text {nd }}$ Annual Meeting of the Transportation Research Board, Washington, D.C., 11-15 January 2003. 